\title{
Erratum to: Dietary magnesium restriction reduces amygdala-hypothalamic GluN1 receptor complex levels in mice
}

\author{
Maryam Ghafari · Nigel Whittle • András G. Miklósi • \\ Caroline Kotlowski - Claudia Schmuckermair · Johannes Berger • \\ Keiryn L. Bennett · Nicolas Singewald · Gert Lubec
}

Published online: 26 June 2014

(C) Springer-Verlag Berlin Heidelberg 2014

\section{Erratum to: Brain Struct Funct}

\section{DOI 10.1007/s00429-014-0779-8}

The last name of Caroline Kotlowski, the fourth author of this paper, was inadvertently misspelled when this article was originally published. The correct spelling is "Kotlowski".

The online version of the original article can be found under doi:10.1007/s00429-014-0779-8.

M. Ghafari · A. G. Miklósi · C. Kotlowski · G. Lubec ( $₫)$ Department of Pediatrics, Medical University of Vienna, Währinger Gürtel 18, 1090 Vienna, Austria

e-mail: gert.lubec@meduniwien.ac.at

N. Whittle $\cdot$ C. Schmuckermair $\cdot$ N. Singewald Department of Pharmacology and Toxicology and Center for Molecular Biosciences, University of Innsbruck,

Peter-Mayr Straße 1/1 Stock, 6020 Innsbruck, Austria

J. Berger

Department of Pathobiology of the Nervous System, Center for Brain Research, Medical University of Vienna, Spitalgasse 4, 1090 Vienna, Austria

K. L. Bennett

CeMM Research Center for Molecular Medicine of the Austrian Academy of Sciences, Lazarettgasse 14, AKH Building BT 25.3, 1090 Vienna, Austria 